\title{
DOE SOLVENT HANDBOOK INFORMATION SHEET
}

\section{Angela A. Chavez \\ Idaho National Engineering Laboratory \\ P.O. Box 1625 \\ Idaho Falls, ID 83415-2108}

\section{DISCLAIMER}

This report was prepared as an account of work sponsored by an agency of the United States Government. Neither the United States Government nor any agency thereof, nor any of their employees, makes any warranty, express or implied, or assumes any legal liability or responsibility for the accuracy, completeness, or usefulness of any information, apparatus, product, or process disclosed, or represents that its use would not infringe privately owned rights. Reference herein to any specific commercial product, process, or service by trade name, trademark, manufacturer, or otherwise does not necessarily constitute or imply its endorsement, recommendation, or favoring by the United States Government or any agency thereof. The views and opinions of authors expressed herein do not necessarily state or reflect those of the United States Government or any agency thereof. 


\section{DOE/DOD Solvent Utilization Handbook}

Solvents and cleaners are used in the Department of Defense (DOD) and the Department of Energy-Defense Program (DOE-DP) inaintenance facilities for removing wax, grease, oil, carbon, machining fluids, solder fluxes, mold releases, and other contaminants before repairing or electroplating parts. Private industry also uses cleaners and degreasers for surface preparation of various metals. Growing environmental and worker safety concerns have brought attention to these solvents and cleaners, most of which are classified as toxic. Tightening government regulations have already excluded the use of some chemicals, and restrict the use of various halogenated hydrocarbons because of their atmospheric-ozone depleting effects, as well as their cancer-related risks.

As a result, a program was established to develop an efficient, easily accessible, electronic solvent utilization handbook. This is being accomplished by: a) identifying solvents (alternatives) that are not currently restricted by government regulations for use at DOE-DP facilities, DOD facilities, and private industry, b) evaluating their cleaning performance, c) evaluating their corrosivity, d) evaluating their air emissions, e) evaluating the possibility of recycling or recovering all or portions of the alternative degreasers, f) testing substitute solvents compatibility with non-metallic materials, g) inputting all of the data gathered (including previous biodegradability information) into a database, and $h$ ) developing a methodology for efficient, widespread access to the data base information system.

The first step was to screen candidate substitutes. Testing was conducted only on solvents which met the following criteria: 1) have a minimum flash point of $200 \mathrm{~F}, 2$ ) contain no hazardous components, and 3) contain no aromatics or halogenated comfounds. Samples of the eligible, alternative solvents were requested for subsequent evaluations. The first studies were conducted to determine the cleaning performance capabilities of the alternative solvents. These cleanin; performance tests were conducted with 16 contaminants. The products that removed $95 \%$ or more of the contaminant in 8 or more cases during a 30 minute test, were subjected to corrosion tests.

Next, immersion corrosion tests were conducted on 26 metal alloys, including copper CDAlO1 with a $\mathrm{Sn} / \mathrm{Pb}$ solder coating. The metal alloys chosen for testing are representative of the alloys most frequent7y used in DOE-DP, nuclear weapons complexes, DOD weapons refurbishment facilities, and private industry. The methods for the corrosion testing were taken from the American Society of Testing and Materials (ASTM) procedure F4830-87. The corrosion rates were calculated using ASTM G31. The corrosion limits were taken from MIL-C-87937, which 1ists five of the metals included in the Solvent Utilization Handbook subtask testing. The alternatives passed the corrosion test if they passed for these five metals (viewed by MIL-C-87937 as the worst-case scenario), regardless of the effect on other metais tested.

a Work supported by the U.S. Department of Energy, Office of Technology Development, under DOE Idaho Field Office, Contract DE-ACO7-76ID01570. 
Those products which passed the immersion corrosion tests were evaluated for volatile organic compound (VDC) emissions. The VOC emission testing was performed using a modified headspace gas chromatography and gas chromatograph mass spectroscopy technique. The modified technique will be used to provide qualitative and quantitative information of volatile organic compounds in the head space. Headspace analysis is the static sampling of the vapor phase in thermodynamic equilibrium with the liquid phase. Headspace analysis is often used to analyze for volatile organic compounds in aqueous samples and can determine micrograms per liter (ppb) in solution. In this study, the concentration of analyte in the headspace, not in solution, was determined. Static headspace analysis was chosen over dynamic headspace (purge and trap) analysis because of its simplicity and because it more closely models the conditions of the cleaning process.

Solvents were initially screened using gas chromatography mass spectroscopy (GC/MS) with semiquantitative evaluation of the constituents found. Quantitative analysis were performed on each solvent substitute after the screening process using GC or GC/MS. Gas chromatography conditions and column selection are being optinized for each solvent substitute to reduce analysis time and improve quantitation.

Quantitative data for each solvent is being evaluated to determine applicability to OSHA and/or EPA regulations. Emission control technologies will be pursued for the identified solvents which exceed permissible exposure limits (PEL) and threshold limit values (TLV). The EPA has not yet established emission standards for toxic air pollutants therefore PELs and TLVs will be used for these standards.

The alternative cleaners were also evaluated for their amenability to existing recycle/recovery processes to ultimately estimate the amount of waste which will be generated, as well as the amount of cleaner/degreaser that users will be required to purchase. The scope of investigation for distillation included examining spent and fresh solvents to determine which method should be recommended for solvent recovery application. Possible distillation methods include precision rectification and azeotropic and extractive distillation. For membrane separations technology, microfiltration, ultrafiltration (UF), and nanofiltration were to be examined to determine the feasibility of using these processes for solvent recovery. Fresh, spent, and recovered solvents were analyzed by high pressure liquid chromatography (HPLC) to compare their characteristics.

Due to the difficulties associated with obtaining true spent solvents, tests were conducted on simulated spent solvents. For paint strippers, paint chips obtained from a solid $\mathrm{CO}_{2}$ blasting paint removing demonstration project were dissolved in fresh solvents to generate simulated spent solvents. For biodegradable cleaners, wax was dissolved in fresh solvents to generate simulated spent solvents.

Distillation tests demonstrated a general feasibility for recovery of the substitute solvents. For single-component paint strippers, the recovery procedure is a relatively simple, single-temperature distillation/precision rectification. For multi-component paint strippers, distillation/precision rectification at multiple temperatures is needed. For either single- or multicomponent paint strippers, vacuum distillation may be required, depending on the thermal stability of the solvent components. 
Distillation recovery of biodegradable cleaners is not as straight forward. Tests show that foaming is likely to be a problem and an antifoaming agent would be necessary to break the foam in the distillation column. An appropriate antifoaming agent is being sought at the present time.

Preliminary membrane separations tests show that, using a membrane made of material compatible with the solvent, UF can remove contaminants in the spent solvent. However, two problems appear to exist that will need to be solved before a practical membrane process can be developed for solvent recovery applicatior. First, current commercial membranes are designed primarily for aqueous system applications. A commercial membrane for organic solvent application is yet to be developed. Second, for one membrane (made of cellulose acetate) that is compatible with several substitute solvents tested, the system pressure required to obtain measurable flux was excessive (over 600 psi versus typical UF pressures of less than 100 psi).

HPLC analysis of fresh, spent, and recovered substitute solvents is still ongoing to verify the integrity of the recovered solvents.

The data gathered from this testing was placed into a data base. The data base is accessible through a modem or through an internet system. EG\&G Idaho, Inc., will have an IBM Model 95 computer set up solely to work as a server. This will allow the system user to access the system faster and easier. This data base will have a query capability allowing the user to search for and access the specific information that is of most importance to that user. This data base will also have the capability of being a "living document". The system is written in $C$ Language so that it could be easily upgraded to a mini and/or a fult computer. 

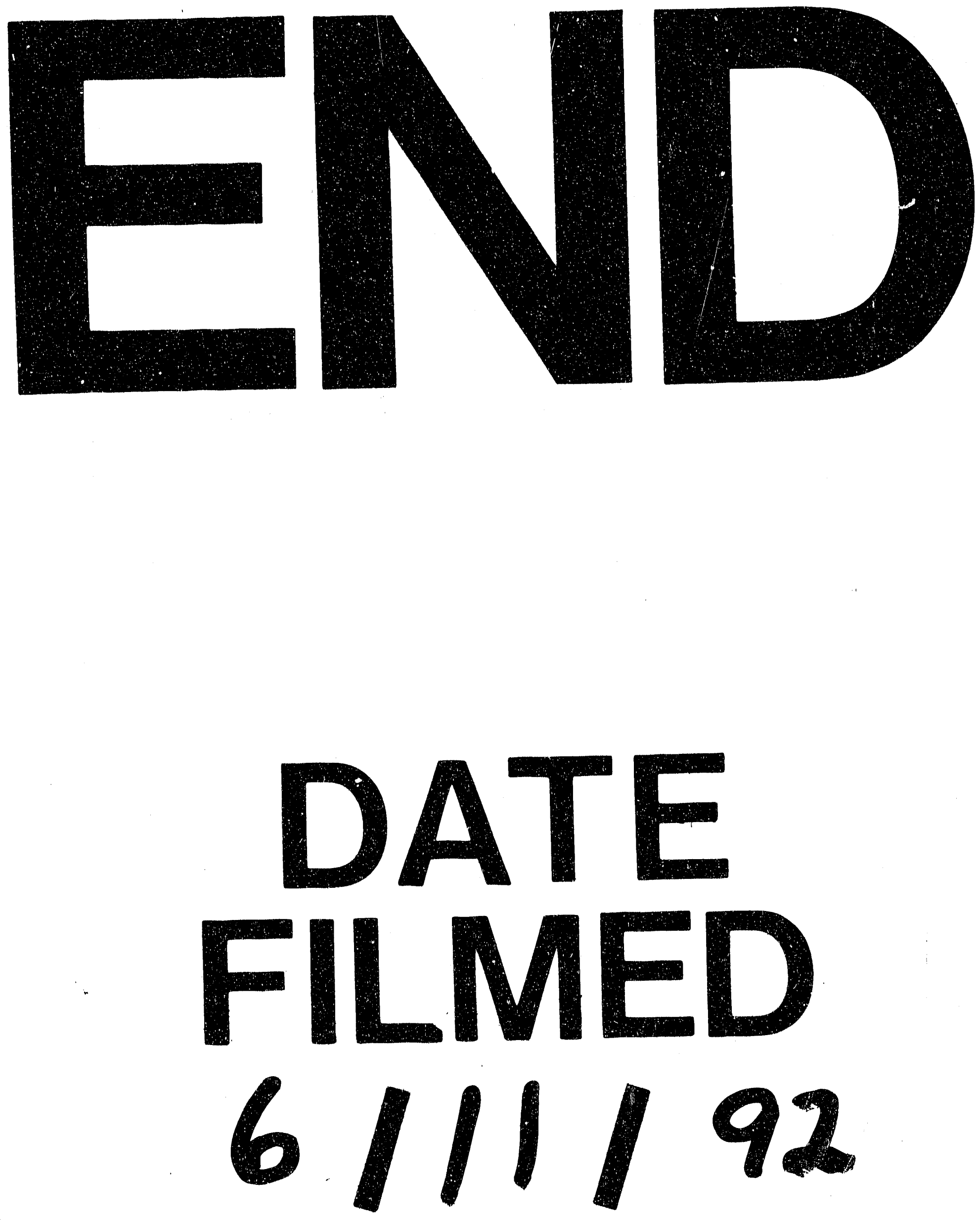
